\title{
The spread of fear: Symbolic generalization mediates graded threat-avoidance in specific phobia
}

\author{
Simon Dymond ${ }^{1}$, Michael W. Schlund ${ }^{2,3}$, Bryan Roche ${ }^{4}$, and Robert Whelan ${ }^{5}$ \\ ${ }^{1}$ Department of Psychology, Swansea University, Swansea, UK \\ ${ }^{2}$ Department of Behavioral Psychology, Kennedy Krieger Institute, Baltimore, USA \\ ${ }^{3}$ Department of Behavior Analysis, University of North Texas, Denton, USA \\ ${ }^{4}$ Department of Psychology, National University of Ireland, Maynooth, Maynooth, Ireland \\ ${ }^{5}$ Trinity Centre for Bioengineering, Trinity College Dublin, Dublin, Ireland
}

\begin{abstract}
Overgeneralization of fear and threat-avoidance represents a formidable barrier to successful clinical treatment of anxiety disorders. While stimulus generalization along quantifiable physical dimensions has been studied extensively, less consideration has been given to symbolic generalization, in which stimuli are indirectly and arbitrarily related. The present study examined whether the magnitude and extent of symbolic generalization of threat-avoidance and threat-beliefs differed between spiderphobic and nonphobic individuals. Initially, participants learned two sets of stimulus equivalence relations $(\mathrm{A} 1=\mathrm{B} 1=\mathrm{C} 1 ; \mathrm{A} 2=\mathrm{B} 2=\mathrm{C} 2)$. Next, one cue $(\mathrm{B} 1)$ was established as a conditioned stimulus $(\mathrm{CS}+$; threat) that signalled onset of spider images and prompted avoidance, and another cue (B2) was established as a CS- (safety cue) that signalled the absence of such images. Subsequent testing showed that phobics compared to nonphobics exhibited greater symbolic generalization of threatavoidance to threat cues $\mathrm{A} 1$ and $\mathrm{C} 1$ (indirect $\mathrm{CS}+$ threat cues related via symmetry and equivalence, respectively), while all individuals showed nonavoidance to indirect safety cues A2 and C2. The enhanced symbolic generalization of threat-beliefs and avoidance behaviour observed in spider phobics warrants further investigation.
\end{abstract}

Keywords: Fear conditioning; Avoidance; Threat; Symbolic generalization; Pathway; Spider fear.

Fear conditioning is a widely used paradigm to study the expression and modulation of nonadaptive fear such as that seen in anxiety disorders and specific phobia (e.g., Beckers, Krypotos, Boddez, Effting, \& Kindt, 2013). The expression of conditioned fear may often arise in the absence of direct pairing between a previously neutral conditioned stimulus (CS), such as a tone, and an aversive unconditioned stimulus (US), such as shock
(Askew \& Field, 2008; Muris \& Field, 2011). Alternative "indirect pathways" to fear, like instruction and observation (Askew \& Field, 2008), readily elicit fear indistinguishable from directly conditioned fear (Olsson \& Phelps, 2004, 2007). Once acquired, fear learning readily generalizes from the CS to untrained, related stimuli along perceptual (e.g., shape) and conceptual/semantic dimensions (e.g., categories and concepts) in both

Correspondence should be addressed to Simon Dymond, Department of Psychology, Swansea University, Swansea SA2 8PP, UK. E-mail: s.o.dymond@swansea.ac.uk

We thank Jasper Robinson for helpful comments, and Rachel Downs, Amie-Louise Prior, Kelly-Marie Davies, and Jodie Withers for assistance with data collection. Robert Whelan is now at Department of Psychiatry, University of Vermont, 1 South Prospect Street, Burlington, VT 05401, USA. 
healthy volunteers (Dunsmoor, Mitroff, \& LaBar, 2009; Dunsmoor, White, \& LaBar, 2011; Vervliet, Kindt, Vansteenwegen, \& Hermans, 2010) and panic disorder patients (Lissek et al., 2010).

Fear generalization reflects an inability to withhold fear responses to CSs based on perceptual/ conceptual stimulus generalization (Lissek et al., 2005) and is thought to maintain ongoing anxiety. In addition, heightened threat anticipation or appraisal (MacLeod \& Cohen, 1993), as seen in specific phobia, may enhance the ability to detect generalized fear signals indirectly related to the feared CS (Lissek et al., 2005, 2010). However, little is known about fear generalization that occurs via arbitrary, symbolic dimensions (Dymond \& Roche, 2009). Symbolic stimulus generalization differs from conceptual stimulus generalization (e.g., Dunsmoor et al., 2009, 2011) because it involves the intraexperimental learning of symbolic relational categories that consist of arbitrary, physically dissimilar stimuli that are not already members of preexisting real-world concepts or categories. The detection and generalization of fear-relevant (threat) and irrelevant (safety) cues acquired indirectly occur along symbolic dimensions when, for instance, an individual with spider phobia shows fear and avoidance not only of the word "spider" but also of related stimuli, such as pictures of spiders, names of different types of spiders, a real spider never seen before, and places where spiders might be found. In this scenario, while conditioned fear may or may not have been directly learned, the generalization of fear (and behavioural avoidance) from the CS occurs along symbolic dimensions. As a result, phobic fear and avoidance occur in the presence of a wide range of stimuli and situations based on the actual and, more often than not, inferred presence of spiders. Given that indirect pathways are often implicated in the origin of phobic fear (Merckelbach, Arntz, Arrindell, \& de Jong, 1992; Merckelbach, Arntz, \& de Jong, 1991), we might expect the relative magnitude of symbolic generalized fear to differ between phobic groups.

We sought to address this by investigating behavioural tendencies to engage in avoidance of stimuli indirectly related to an aversive CS, as an instantiation of fear (Beckers et al., 2013; Grillon, Baas, Cornwell, \& Johnson, 2006). Excessive avoidance is a central diagnostic feature in the acquisition and maintenance of anxiety disorders (Mineka \& Oehlberg, 2008), and we compared the generalized threat-avoidance tendencies of groups of spider-phobic and nonphobic participants when a simple avoidance response cancelled upcoming spider pictures (US). Avoidance of actual spiders or places where spiders may be found, including situations in which the presence of spiders is inferred and not directly encountered, are key defining features of phobic avoidance (LeBeau et al., 2010; Stinson et al., 2007). Ultimately, an individual with spider fear fails to learn accurate threat-relevant information about the potential likelihood of encountering spiders (Thorpe \& Salkovskis, 1997), which suggests that fear generalization and subsequent avoidance may be enhanced for such individuals.

While generalized avoidance of degraded coloured circles along a physical continuum between $\mathrm{CS}+$ and CS- has been reported (Lommen, Engelhard, \& van den Hout, 2010), we employed the symbolic generalization pathway in which physically dissimilar stimuli that are indirectly related to the CS occasion avoidance (Augustson \& Dougher, 1997; Dougher, Augustson, Markham, Greenway, \& Wulfert, 1994; Dymond \& Rehfeldt, 2000; Dymond, Roche, Forsyth, Whelan, \& Rhoden, 2007; Dymond, Schlund, Roche, De Houwer, \& Freegard, 2012; Dymond et al., 2011; Hooper, Saunders, \& McHugh, 2010; Rodriguez-Valverde, Luciano, \& Barnes-Holmes, 2009). Using a fear-irrelevant avoidance paradigm, Dymond et al. (2011) showed that establishing avoidance with one stimulus in a network also produces avoidance of all indirectly related stimuli via symbolic generalization. Participants were first trained and tested for the formation of stimulus equivalence relations consisting entirely of abstract, arbitrary stimuli (labelled here, for purposes of clarity, with the alphanumerics, $\mathrm{A} 1=\mathrm{B} 1=\mathrm{C} 1 ; \mathrm{A} 2=\mathrm{B} 2=\mathrm{C} 2$ ). Several decades of research on stimulus equivalence and other verbal relations has shown that when language-able humans are taught a series of 
interconnected discriminations, the stimuli involved often become related to each other in ways not explicitly trained (Dymond \& Roche, 2013; Hayes \& Hayes, 1992; Sidman, 1994). To illustrate, if choosing Stimulus B1 in the presence of Stimulus A1 is taught (i.e., A1-B1), and choosing Stimulus C1 in the presence of Stimulus A1 (i. e., A1-C1) is also taught, it is likely that untrained relations will emerge between $\mathrm{B} 1$ and $\mathrm{A} 1, \mathrm{C} 1$, and $\mathrm{A} 1$ ("symmetry"), B1 and $\mathrm{C} 1$, and $\mathrm{C} 1$ and $\mathrm{B} 1$ ("combined symmetry and transitivity", or "equivalence"), in the absence of any feedback. When this occurs, a stimulus equivalence relation is said to have formed among the relata. Emergent relations such as these may help to explain the symbolic generalization that readily occurs in fear and avoidance when indirectly related, physically dissimilar stimuli such as words and pictures occasion the same responses without direct training.

During the avoidance-learning phase in Dymond et al. (2011), one stimulus (B1) was followed by aversive images and sounds unless a response was made (pressing the space-bar once), and another (B2) was not. When the avoidance response was performed, B1 was removed from the screen, and the aversive stimuli were omitted. Symbolic generalization of threat-avoidance was then tested with presentations of stimuli not been present during the avoidance-learning phase. All participants readily made the threat-avoidance response to $\mathrm{C} 1$ (indirectly related to $\mathrm{B} 1$ ) and not to $\mathrm{C} 2$ (indirectly related to B2), and measures of threat-beliefs (expectancies of aversive images following avoidance and nonavoidance) paralleled their avoidance behaviour.

The present study sought to investigate the magnitude and extent of symbolic generalization of threat-avoidance by contrasting behavioural responses and outcome ratings of spider-phobic and nonphobic individuals. The study, therefore, is intended to extend upon the findings of Dymond et al. (2011), by examining the in vivo process of threat-avoidance generalization as it unfolds differentially across two specific subclinical populations exposed to stimuli whose aversive functions have been established naturalistically outside the laboratory. We hypothesized that the magnitude of threat anticipation, manifest as generalized avoidance responses and outcome ratings, would be greater in spider-phobic participants because of increased motivation to avoid both actual spiders and cues that might predict spiders (i.e., a form of hypervigilant avoidance of potential encounters with spiders, or settings where they might be found). Also, we predicted that spiderphobic participants would acquire avoidance in fewer conditioning trials because of the increased aversive intensity of the spider picture USs. Finally, we hypothesized that participants' ratings of the likelihood of the US following learned and generalized threat and safety cues would be modulated by spider fear status, with spider-phobic participants expecting spider pictures more often after all cues than nonphobic participants.

\section{Method}

\section{Participants}

Participants were recruited from a large sample of undergraduate psychology students administered the Fear of Spiders Questionnaire (FSQ; Szymanski \& O'Donohue, 1995). The FSQ is an 18-item questionnaire assessing spider phobia (scoring range $=0-126$ ) with good internal consistency (Cronbach's alpha $=.92$ ) and reliability (.89; Muris \& Merckelbach, 1996). Participants indicated their willingness to attend a testing session during which pictures of spiders would be present; individuals with the highest and lowest FSQ scores were invited to attend.

The final sample consisted of 32 high-spiderfearful (HSF) and 32 low-spider-fearful (LSF) individuals, 50 women and 14 men, ranging in age from 18 to 30 years old. Group assignment was based on participants' FSQ scores: The HSF group's mean score $(M=96.4, S D=16.6)$ differed from the LSF group's mean score $(M=3.4, S D=$ 4.3), $t(62)=30.66, p<.001, r=.93$. Such scores are consistent with previous studies of spider fear (e.g., Pace-Schott, Verga, Bennett, \& Spencer, 2012; Rinck \& Becker, 2007; Vansteenwegen et al., 2007). Exclusion criteria included any history of psychopathology, any clinically significant physical or medical impairment, and current 
use of psychotropic medication. Participants were reimbursed with partial course credit on completion of the study. The Department of Psychology Ethics Committee at Swansea University approved the study, and all participants provided written informed consent.

\section{Apparatus and stimuli}

A computer program written in Visual Basic ${ }^{\circledR} 6.0$ controlled all stimulus presentations and recorded all responses. Six nonsense words comprised the stimuli used during stimulus equivalence training and testing (JOM, CUG, VEK, PAF, ZID, $\mathrm{BEH})$. Stimuli were presented in capitals, in uppercase bold size 24 Arial font, and counterbalanced across participants (Dymond et al., 2011). Ten spider pictures, six ${ }^{1}$ selected from the International Affective Picture System (IAPS; Lang, Bradley, \& Cuthbert, 2005) and four via a Google ${ }^{\circledR}$ image search were used during the avoidance acquisition and generalization testing phases.

\section{Procedure}

Phase 1: Equivalence training and testing. A delayed matching-to-sample procedure was used to train a series of conditional discriminations (A1-B1, $\mathrm{A} 1-\mathrm{C} 1, \mathrm{~A} 2-\mathrm{B} 2$, and $\mathrm{A} 2-\mathrm{C} 2)$ and to test for the emergence of combined symmetry and transitivity (i.e., stimulus equivalence) relations (B1-C1, $\mathrm{C} 1-\mathrm{B} 1, \mathrm{~B} 2-\mathrm{C} 2$, and $\mathrm{C} 2-\mathrm{B} 2$; see Figure 1). Participants were first given the following onscreen instructions:

In a moment some words will appear on the screen. Look at the words at the top of the screen, and then look at the two words at the bottom of the screen, on the left and right. Choose one of the two words at the bottom of the screen by clicking on it. Sometimes the computer will give you feedback, and at other times it will not. However, you can get all of the tasks without feedback correct by carefully attending to the tasks with feedback.

On every trial, a nonsense word (A1 or A2) first appeared in the top centre of the computer screen (called the sample stimulus) for 1,500 ms and was immediately followed by two further nonsense words (B1 and $\mathrm{B} 2$ or $\mathrm{C} 1$ and $\mathrm{C} 2$, respectively) positioned in the bottom left and right corners of the screen (called the comparison stimuli). The comparisons remained on screen until a response was made (i.e., clicking on one with the computer mouse). Correct selections were followed by the word, "Correct", while incorrect selections were followed by the word, "Wrong". This feedback was displayed in size 14 Arial black font within a $4.5 \times 2-\mathrm{cm}$ square in the middle of the screen for $2 \mathrm{~s}$ and was followed by an intertrial interval (ITI) of $2 \mathrm{~s}$. A brief audible "beep" also accompanied "Correct". In the presence of A1, clicking on B1, not B2, was correct; in the presence of A2, clicking on $\mathrm{B} 2$, not $\mathrm{B} 1$, was correct; in the presence of $\mathrm{A} 1$, clicking on $\mathrm{C} 1$, not $\mathrm{C} 2$, was correct; and, in the presence of $\mathrm{A} 2$, clicking on $\mathrm{C} 2$, not $\mathrm{C} 1$, was correct (Figure 1). All four trial types (A1-B1, $\mathrm{A} 1-\mathrm{C} 1, \mathrm{~A} 2-\mathrm{B} 2, \mathrm{~A} 2-\mathrm{C} 2)$ were presented in a block of eight trials (each presented twice) in a pseudorandom order, with the constraint that the same task was not presented across more than two consecutive trials. Blocks were repeated until participants made eight consecutively correct responses.

On meeting criterion, a block of 16 trials was presented that tested for the emergence of combined symmetry and transitivity (i.e., stimulus equivalence) relations. It was predicted that participants would select $\mathrm{C} 1$ given $\mathrm{B} 1, \mathrm{~B} 1$ given $\mathrm{C} 1, \mathrm{C} 2$ given $\mathrm{B} 2$, and $\mathrm{B} 2$ given $\mathrm{C} 2$ (Figure 1). Each of the four test tasks (B1-C1, C1-B1, $\mathrm{B} 2-\mathrm{C} 2$, and $\mathrm{C} 2-\mathrm{B} 2)$ was presented four times in the absence of feedback. Mastery criterion to infer the emergence of stimulus equivalence relations was set at 16 consecutive correct responses. If participants failed to achieve this, they were reexposed to training and repeated testing until criterion was met.

Phase 2: Pavlovian acquisition. The purpose of this phase was to establish $\mathrm{B} 1$ as $\mathrm{CS}+$ by pairing it with spider pictures and to establish $\mathrm{B} 2$ as CS- by pairing it with the absence of spider pictures (Figure 1). Participants were given the following instructions:

\footnotetext{
${ }^{1}$ IAPS identifiers: 1200, 1201, 1205, 1220, 1230, and 1240.
} 
Phase 1: Equivalence Training \& Testing

Avoidance cues

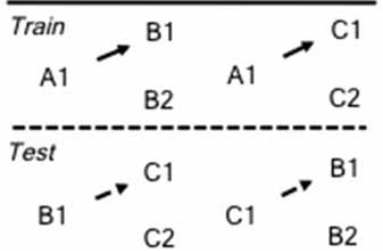

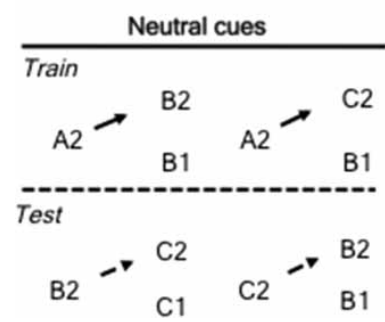

Phase 2: Pavlovian Acquisition

Phase 3: Avoidance Acquisition

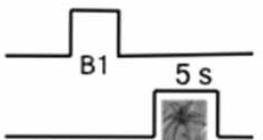

$2 \mathrm{~s}$

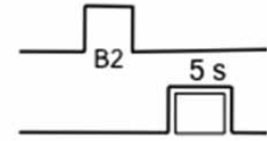

B2
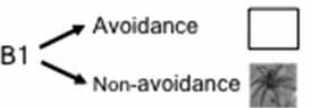

A1

(C1)

Phase 4:

Avoidance Generalization Testing
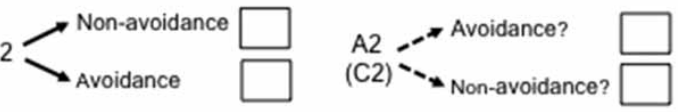

\section{$2 \mathrm{~s}$}

Figure 1. Overview of the experimental procedure (Phases 1-4). Solid arrows in avoidance acquisition indicate cue-response-outcome training, dashed arrows in avoidance generalization testing indicate cue-response-outcome testing, "?" indicate predicted avoidance/non-avoidance behaviour, and squares indicate blank screens.

In a moment, you will be presented with some nonsense words and pictures of spiders. The pictures of spiders are of real spiders and may be considered upsetting to some people. The pictures will follow nonsense words. Your task is to pay attention to the nonsense words and what follows them on the screen. Later, you will be able to cancel the pictures before they are presented, but for now, we would like you to just sit and concentrate on the screen. If you have any questions, please ask the experimenter now. When you are ready to begin, press any key to continue.

Each CS was presented for $2 \mathrm{~s}$, followed by a $1.5-\mathrm{s}$ blank screen and a 5 -s presentation of either a $600 \times 800$-pixel photograph of a spider following $\mathrm{B} 1$ or a blank screen following B2, respectively. The ITI varied randomly between 11 and $15 \mathrm{~s}$ inclusive (i.e., $11,12,13,14$, or $15 \mathrm{~s}$, with equal probability). Each CS was presented three times in a pseudorandom order, with the constraint being that no more than two consecutive presentations of each stimulus could occur.

Phase 3: Avoidance acquisition. The purpose of this phase was to learn to avoid B1 and to learn safety (nonavoidance) to B2 (Figure 1). Participants were given the following instructions:

Now that you have seen some of the nonsense words and pictures, your task is to learn to cancel some of the pictures before they are presented, by pressing the space bar. Later, you will be asked to make some ratings using a slider-scale. Please follow the onscreen instructions and make your ratings as honestly as possible. If you have any questions, please ask the experimenter now. When you are ready to begin, press any key to continue.

Once participants had clicked the screen to proceed, a blank screen was displayed for 1,700 ms. Next, either B1 or B2 appeared in the centre of the screen for $5 \mathrm{~s}$. If participants pressed the space bar while either stimulus was present, then the screen cleared, and the words "Picture Cancelled" appeared for $2 \mathrm{~s}$. If participants did not press the space bar, the B1 or B2 stimulus was followed by a 2 -s interval, after which either a $600 \times 800$-pixel photograph of a spider (following B1) or a blank screen was presented for $2 \mathrm{~s}$ (following B2). The B1 and B2 stimuli were presented in a pseudorandom order (i.e., no more than two consecutive exposures to either) until participants made five consecutive avoidance responses during presentations of B1 and five consecutive nonavoidance responses during presentations of B2. Tasks were re-presented until criterion was met or until a total of 36 trials were presented, whichever came first.

Participants then answered four questions, which were displayed in a random order, about 
the likelihood of spider pictures being presented both in the assumed presence and in the absence of avoidance during B1 and B2 trials. The questions read as follows: "How likely is it that a picture of a spider will be presented if [B1/B2] appears and you [do/do not] press the space bar? Please use the slider scale below to rate how likely you think it is, where 1 is very unlikely and 10 is very likely." Participants moved the slider scale with the computer mouse and confirmed their rating by clicking on a button labelled "confirm [value chosen]".

Phase 4: Avoidance generalization testing. Phase 4 began immediately after Phase 3. Participants were reminded that they could continue to choose to cancel some pictures, but not others, by pressing the space bar. As before, a blank screen was displayed for $1,700 \mathrm{~ms}$, followed by a block of trials that presented $\mathrm{A} 1, \mathrm{C} 1, \mathrm{~A} 2$, and $\mathrm{C} 2$ (Figure 1). These stimuli were related via symmetry (A1 and $\mathrm{A} 2)$ and equivalence ( $\mathrm{C} 1$ and $\mathrm{C} 2)$ to the $\mathrm{CS}+$ (B1) and CS- (B2). Symmetry and equivalence cues were presented separately to test whether differential rates of generalization occurred by virtue of the indirect relatedness of cues. That is, symmetry cues are bidirectionally related to trained cues while equivalence cues are indirectly related via a mediating cue or node, and differential generalization is often observed (Dymond \& Rehfeldt, 2000).

All stimuli remained on screen for $5 \mathrm{~s}$ if no avoidance response occurred. If a participant pressed the space bar during any stimulus, then the screen cleared, and the words "Picture Cancelled" appeared for $1.5 \mathrm{~s}$. Because this was a test phase, spider pictures never followed not pressing the space bar. Six presentations of each stimulus were given in a 24-trial block. All trials were presented in a pseudorandom order with the only constraint that no more than two consecutive trials of the same type could occur. Eight questions about the likelihood of spider pictures being presented both with and without the avoidance response during $\mathrm{A} 1, \mathrm{C} 1, \mathrm{~A} 2$, and $\mathrm{C} 2$ presentations were then displayed, and, once trials had been completed, participants were debriefed.

\section{Statistical analyses}

In Phase 1 , independent-samples $t$ tests were performed on the number of trials to reach criterion and the number of stimulus equivalence test exposures. During Phases 3 and 4, we focused our analyses on the mean number of trials in which the avoidance response was performed and the mean ratings made when the avoidance response was assumed to be present and absent. Data for the learned stimuli were averaged across the entire avoidance acquisition phase (which varied in length depending on whether or not participants met criterion within 36 trials). Multivariate $F$ values, Pillai's trace, are reported for all main effects and interactions, along with two follow-up paired-sample $t$ tests corrected for multiple comparisons (Bonferroni, $p=.025$ ).

\section{Results}

\section{Equivalence training and testing (Phase 1)}

Both the number of trials to reach the training criterion (HSF: $M=81.84, S D=78.20 ; \mathrm{LSF}$ : $M=44.75, \quad S D=31.81), \quad t(62)=2.48, \quad p=.01$, $r=.090$, and the number of stimulus equivalence test exposures (HSF: $M=4.00, S D=3.68$; LSF: $M=2.38, \quad S D=1.60), \quad t(62)=2.29, \quad p=.02$, $r=.077$, were significantly different between the two groups. These findings were not predicted; the matching-to-sample training and testing task involved nonsense words, and no spider pictures were presented during this phase.

\section{Avoidance acquisition and generalization testing (Phases 3 and 4)}

Five HSF participants and 6 LSF participants failed to meet the avoidance acquisition criterion within 36 trials and were excluded from further analysis. This resulted in a final $n=27$ (HSF) and $n=26$ (LSF), respectively. In general, HSF participants required significantly fewer avoidance acquisition trials than LSF participants, $t(51)=$ 2.056, $p<.05$.

Avoidance behaviour. Overall, results showed that both groups demonstrated similar levels of avoidance of learned threat cues but the HSF 
group evidenced greater symbolic generalization (Figure 2A). Across acquisition and testing phases, both groups made low levels of avoidance to the learned and generalized (symmetry and equivalence) safety cues (Figure 2). As predicted, there were no significant main effects or interaction in the analysis of the safety cues.

However, both groups showed substantial avoidance responding to both the learned and generalized threat cues (Figure 2); here, we observed a main effect of cue, $F(2,50)=30.734, p<.001$, group, $F(2,50)=16.316, p<.001$, and a Group $\times$ Cue interaction, $F(2,50)=6.056, p<.01$. Follow-up $t$ tests showed that the interaction was driven by higher levels of avoidance in the HSF group than in the LSF group to the threat cues related via symmetry, $t(51)=4.595, p<.001$, and equivalence, $t(51)=3.299, p<.01$.

Ratings. The analysis of ratings made in the assumed presence of avoidance (Figure 2B) of the learned and generalized safety cues and learned and generalized threat cues revealed no significant main effects or interaction. Analysis of ratings made for the safety cues in the assumed absence of avoidance (Figure 2C) revealed a main effect of cue, $F(2,50)=228.444, p<.001$, and no Cue $\times$ Group interaction, while analysis of ratings made for the threat cues revealed a main effect of cues, $F(2, \quad 50)=136.704, \quad p<.001$, and a Cue $\times$ Group interaction, $F(2,50)=5.364, p<.01$. Follow-ups showed that the groups differed significantly in ratings made of the likelihood of encountering spider images in the absence of avoidance to the symmetry, $t(51)=4.986, p<.001$, and equivalence, $t(51)=3.635, p=.001$, generalized cues.

Overall, results showed that both groups demonstrated similar levels of avoidance of learned threat cues but the HSF group evidenced greater symbolic generalization. Ratings made of the likelihood of encountering spider pictures in the assumed presence of the avoidance response were similar across groups, but LSF participants tended to give higher ratings in the assumed absence of avoidance to the generalized symmetry and equivalence cues.

\section{Discussion}

Spider-phobic participants required significantly fewer avoidance acquisition trials and exhibited greater magnitude generalized threat-avoidance than nonphobic participants. Both groups' threat beliefs about the inferred likelihood of spiders following the inferred threat cue were similar, yet spider-phobic participants engaged in higher levels of inferred threat-avoidance. Moreover, spider-phobic participants also gave higher threat belief ratings than nonphobic participants of the likelihood of spider pictures following the inferred threat cues when the avoidance response was assumed to be present. These findings show, for the first time, how inference mediates graded threat anticipation in spider fear and how the symbolic generalization pathway gives rise to the spread of fear and avoidance (Dymond \& Roche, 2009). The current study also represents a more ecologically valid replication of Dymond et al. (2011) insofar as the fear of spiders that was shown to symbolically generalize was already established in the learning histories of the participants and was at a high level for the HSF group. In effect, the current findings allow us to conclude with greater confidence that the symbolic generalization of fear is not merely a phenomenon observed using laboratory conditioned stimuli alone, or for fear and avoidance responses irrelevant to common clinical issues.

The fact that the HSF group were significantly slower at reaching the equivalence training criterion and required more test exposures than the LSF group may suggest that informing participants at the outset that the experiment involved spider pictures may have resulted in hypervigilance (Huijding, Mayer, Koster, \& Muris, 2011; Pflugshaupt et al., 2005), at least in the early phases. Later, the HSF group showed greater sensitivity, as evidenced by proportion of avoidance responses and elevated threat belief ratings, to indirectly related stimuli predicting threat than did the LSF group. These between-group differences may partly be due to the increased number of exposures that the HSF group had to Phase 1; to further test this hypothesis, a replication of the 

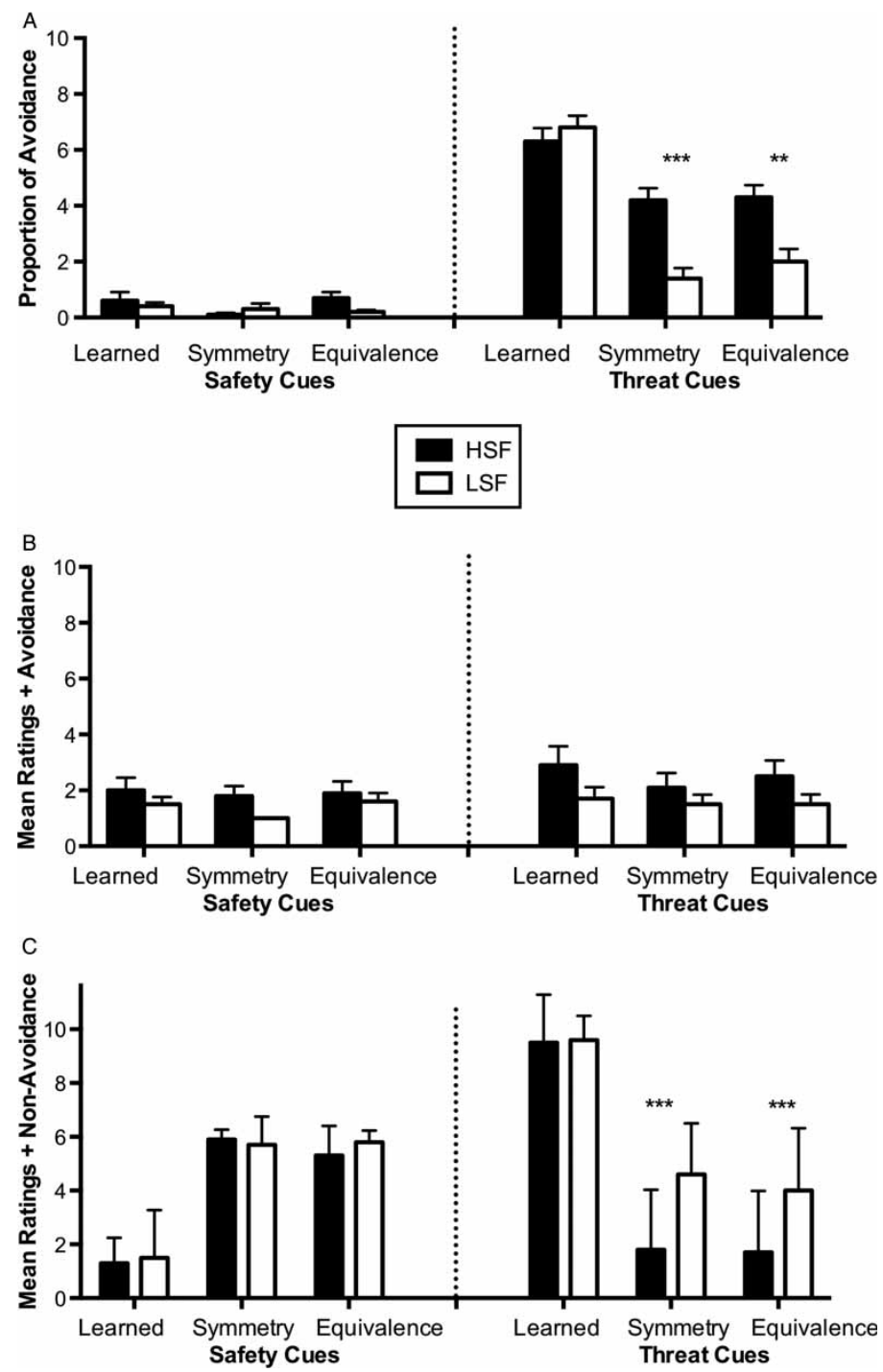

Figure 2. (A) Mean proportion of avoidance to learned, symmetry, and equivalence threat and safety cues during avoidance training and generalization testing, for both groups. (B) Mean ratings of the likelihood of encountering spider images when the avoidance response was assumed to be present, and $(C)$, when assumed to be absent, respectively, for learned, symmetry, and equivalence threat and safety cues during avoidance training and generalization testing, for both groups. HSF = high-spider-fearful individuals; LSF $=$ low-spider-fearful individuals. Bars show standard error of the mean. ${ }^{* 0 * a k} p<.001 .{ }^{* * p} p<.01$.

present procedures in which the number of equivalence training and testing exposures is matched or yoked across groups is warranted. The differences may also be the result of inhibition of arousal to the directly learned and inferred safety stimuli. That is, although groups rarely responded to the safety stimuli, the explicit avoidance and nonavoidance acquisition criteria may have fostered greater awareness of the CS-US contingencies, which is a factor known to mediate fear conditioning outcomes (Raio, Carmel, Carrasco, \& Phelps, 2012). Enhanced contingency awareness may thus have 
influenced inhibition of arousal to the safety stimuli, with concomitant effects on the learned and generalized threat stimuli. These issues warrant further empirical attention.

We failed to detect any statistically reliable trends in threat-belief ratings made in the assumed presence of the avoidance response, but did observe significantly elevated ratings in the assumed absence of avoidance, with the LSF group indicating higher likelihood of spiders following the generalized cues. A possible explanation for this could stem from the fact that the ratings were obtained following a period of extinction during which participants had the opportunity to learn that no spider picture USs would follow the learned or generalized threat cues when avoidance was withheld. The performance of the LSF group in particular supports this explanation: This group evidenced a low level of avoidance of the generalized cues, and their ratings reflected this. It would thus appear important to try and replicate the present findings by measuring US expectancies on a trial-by-trial basis (Vervliet et al., 2010) in order to determine the assumed impact of the extinction test block on ratings.

The present design may have some features in common with sensory preconditioning procedures, which reveal that conditioned responding often emerges in the absence of direct CS-US pairings. Such procedures usually involve three stages. In the first stage, two neutral stimuli are paired (e.g., $\mathrm{A} \rightarrow \mathrm{B}$ ), and then one stimulus (e.g., B) undergoes Pavlovian training and thus becomes a CS. In the final test stage, it is shown that the other stimulus (i.e., A) also elicits conditioned responding, despite it never being directly paired with the US. Backward sensory preconditioning-in which the first stimulus paired (e.g., A) is established as a CS before the second (e.g., B) is presented at test - has also been shown (e.g., Declercq \& De Houwer, 2009; Ward-Robinson \& Hall, 1996; White \& Davey, 1989). On the face of it, the current procedures share some similarities with sensory preconditioning to the extent that one stimulus was established as a CS+ for avoidance and symbolic generalization tested with presentations of stimuli related via symmetry and equivalence relations, all of which were never directly paired with spider picture USs. However, an associative account of the present findings would appear to necessitate the involvement of backward conditioning, which is a notoriously weak effect (J. F. Hall, 1984; see also, Holland, 1990; Spetch, Wilkie, \& Pinel, 1981). Backward associations are required to account for symbolic generalization from $\mathrm{B}$ to $\mathrm{C}$ after $\mathrm{A}-\mathrm{B}$ and $\mathrm{A}-\mathrm{C}$ match-to-sample-based conditional learning, and such associations "are not readily formed" (G. Hall, 1996, p. 248). Alternative accounts of the present data such as mediated generalization (Urcuioli, 1996), which invokes forward conditioning processes to explain $\mathrm{B}-\mathrm{C}$ and $\mathrm{C}-\mathrm{B}$ equivalence (and, presumably, any resulting generalization effects), rely on a particular sequence of training to explain the observed effects. That is, A-B training must precede $\mathrm{A}-\mathrm{C}$ training or "it is unlikely that [the A stimuli would] generate the necessary prospective mediators to support transfer" (Urcuioli, 1996, p. 65). This was clearly not the case in the present study as both $\mathrm{A}-\mathrm{B}$ and $\mathrm{A}-\mathrm{C}$ were presented equally often during the same block of training trials in Phase 1 (BarnesHolmes, Hayes, \& Roche, 2001).

Although a detailed consideration of the relative merits of associative versus functional accounts of the findings is beyond the scope of the present article (but see G. Hall, 1996; Smeets \& BarnesHolmes, 2003), there are other reasons to caution against a sensory preconditioning account. First, such an account would obviously need to explain the observed between-group generalization test differences at test, which could not have been due to other factors known to influence sensory preconditioning outcomes, such as US inflation (White \& Davey, 1989), because both groups received an identical number of Pavlovian training trials. Second, we used a "one-to-many" conditional discrimination training design that tends to reliably lead to the emergence of stimulus equivalence in humans but not necessarily nonhumans (Urcuioli, Zentall, \& DeMarse, 1995). Any associative explanation based on sensory preconditioning of the emergence of combined symmetry and transitivity (B-C and $\mathrm{C}-\mathrm{B})$ test relations would at least need 
to account for the relative absence of such abilities in nonhumans that are otherwise capable of associative learning (G. Hall, 1996). Finally, it should remain an important requirement that any account of the present findings be as parsimonious as possible and generate a high number of testable predictions. In particular, further research is needed on the role of alternative training designs, such as linear-series $(\mathrm{A}-\mathrm{B}, \mathrm{B}-\mathrm{C})$, or the necessity of a prior test for equivalence relations (Dymond \& Rehfeldt, 2000), in generating the present effects. In conclusion, we contend that an account based on symbolic generalization and equivalence relations is parsimonious in that the fear and avoidance functions attached to one member of an equivalence relation readily transferred, for HSF participants rather than LSF participants, to the indirectly related symmetrical and equivalent stimuli by virtue of symbolic generalization operating within the derived relations (Smeets \& BarnesHolmes, 2003).

The present findings may have implications for understanding the aetiology of clinically relevant fear and avoidance. Greater levels of symbolic generalization in spider-phobic participants could be another risk factor for psychopathology (Lissek et al., 2005, 2010). The graded differences in symbolic generalization of threat-avoidance we observed reflect the central role that verbal relational processes play in the transition from healthy, adaptive cognition to psychopathology (Dymond, Roche, \& Bennett, 2013). Traditional cognitive interventions, such as exposure therapy (Craske et al., 2008), directly target the fearful CS but leave underlying networks of stimulus associations intact. Our findings suggest that these associations between directly learned and inferred threat cues can come to dominate the fear and avoidance responses of spider-phobic individuals and may be remarkably resistant to extinction (Hermans, Craske, Mineka, \& Lovibond, 2006). Using the present findings to inform treatment of spider phobia might involve experiential exercises aimed at defusing the meanings of stimuli associated indirectly with fear and with avoidance of spiders or places where spiders might be found (Hayes, Strosahl, \& Wilson,
2011). For instance, cognitive defusion methods such as repeating a word or utterance aloud have proven effective in reducing the negative impact of fear-related thoughts (Masuda, Feinstein, Wendell, \& Sheehan, 2010). If the effects of defusion with fear-relevant, generalized CSs, like the word "spider" or places where spiders might be found, are comparable with those found with cognitive interventions such as combining exposure therapy with, for instance, affect labelling (Kircanski, Lieberman, \& Craske, 2012), then it indicates functional overlap between the present procedures and the language-based processes at work in these studies.

The present study has some minor limitations. The role of the "picture cancelled" feedback screens displayed following all avoidance responses clearly warrant comment as they may have resembled more than just the absence of a scheduled spider picture US and encouraged learning of avoidance to B2. This is unlikely for the following reasons. First, the feedback was clearly inaccurate in the context of the safety stimuli, since spider pictures were never scheduled after these. While participants could still have learned that B2 would not be followed by the US even in the absence of the avoidance response, our data indicate that participants tended to withhold avoidance during B2 presentations at acquisition. Second, the instructions emphasized that participants should learn to press the space bar in the presence of some stimuli but not others, which may have prompted participants to withhold responding during safety cues and hence not encounter the feedback. Third, we employed a stringent acquisition criterion (Dymond et al., 2011) in which a minimum of five consecutive avoidance responses to $\mathrm{B} 1$ was required. This emphasis on the maintenance of avoidance behaviour, combined with a predetermined maximum number of trial exposures, ensured that avoidance of spider pictures occurred under free-operant conditions (Higgins \& Morris, 1984). This was necessary in order to present multiple cues during generalization testing. Fourth, if the feedback screen were sufficient to evoke avoidance of all stimuli then no participants would have met the acquisition criterion. 
While 11 (i.e., 17\%) of participants did not reach criterion, we are confident that the role of such feedback in the acquisition and maintenance of threat-avoidance was minimal, although clearly further research is warranted. Finally, presenting the $\mathrm{CS}+$ and $\mathrm{CS}-$ in the test phase along with the generalization stimuli would have allowed for comparison within rather than across training and testing phases. We chose not to present learned cues in the test phase, which began immediately following acquisition, in order to probe for generalization under extinction conditions with the minimum number of trials needed and to avoid overburdening participants in what was already a long and potentially upsetting experiment. It remains possible, however, that our findings could have been influenced by this arrangement, and future studies that include learned and generalized stimuli at test are warranted (cf. Dymond et al., 2011).

In conclusion, threat-avoidance is differentially mediated by symbolic generalization processes in spider-phobic and nonphobic participants. Levels of avoidance and threat-belief ratings were modulated by spider fear status, with high-spiderfearful participants showing greater magnitude of generalized threat-avoidance behaviour than lowspider-fearful participants. Findings provide support for the role of language processes, such as symbolic generalization, in the aetiology and maintenance of specific phobia.

Original manuscript received 17 January 2013

Accepted revision received 17 April 2013

First published online 23 May 2013

\section{REFERENCES}

Askew, C., \& Field, A. P. (2008). The vicarious learning pathway to fear 40 years on. Clinical Psychology Review, 28, 1249-1265.

Augustson, E. M., \& Dougher, M. J. (1997). The transfer of avoidance evoking functions through stimulus equivalence classes. Journal of Behavior Therapy and Experimental Psychiatry, 28, 181-191.
Barnes-Holmes, D., Hayes, S. C., \& Roche, B. (2001). The (not so) strange death of stimulus equivalence. European Journal of Behavior Analysis, 2, 35-41.

Beckers, T., Krypotos, A.-M., Boddez, Y., Effting, M., \& Kindt, M. (2013). What's wrong with fear conditioning? Biological Psychology, 92, 90-96.

Craske, M. G., Kircanski, K., Zelikowsky, M., Mystkowski, J., Chowdhury, N., \& Baker, A. (2008). Optimizing inhibitory learning during exposure therapy. Behaviour Research and Therapy, 46, 5-27.

Declercq, M., \& De Houwer, J. (2009). Transfer of avoidance responding to a sensory preconditioned cue: Evidence for the role of S-S and R-S knowledge in avoidance learning. Learning and Motivation, 40, 197-208.

Dougher, M. J., Augustson, E., Markham, M. R., Greenway, D. E., \& Wulfert, E. (1994). The transfer of respondent eliciting and extinction functions through stimulus equivalence classes. Journal of the Experimental Analysis of Behavior, 62, 331-351.

Dunsmoor, J. E., Mitroff, S. R., \& LaBar, K. S. (2009). Generalization of conditioned fear along a dimension of increasing fear intensity. Learning $\mathcal{E}^{2}$ Memory, 16, 460-469.

Dunsmoor, J. E., White, A., \& LaBar, K. S. (2011). Conceptual similarity promotes generalization of higher order fear learning. Learning $\&$ Memory, 18, 156-160.

Dymond, S., \& Rehfeldt, R. A. (2000). Understanding complex behaviour: The transformation of stimulus functions. The Behavior Analyst, 23, 239-254.

Dymond, S., \& Roche, B. (2009). A contemporary behaviour analysis of anxiety and avoidance. The Behavior Analyst, 32, 7-28.

Dymond, S., \& Roche, B. (2013). Advances in relational frame theory: Research and application. Oakland, CA: New Harbinger.

Dymond, S., Roche, B., \& Bennett, M. (2013). Relational frame theory and experimental psychopathology. In S. Dymond \& B. Roche (Eds.), Advances in relational frame theory: Research and application (pp. 199-218). Oakland, CA: New Harbinger.

Dymond, S., Roche, B., Forsyth, J. P., Whelan, R., \& Rhoden, J. (2007). Transformation of avoidance response functions in accordance with the relational frames of same and opposite. Journal of the Experimental Analysis of Behavior, 88, 249-262.

Dymond, S., Schlund, M. W., Roche, B., De Houwer, J., \& Freegard, G. (2012). Safe from harm: Learned, instructed, and symbolic generalization 
pathways of human threat-avoidance. PLOS ONE, 7 (10), e47539. doi:10.1371/journal.pone.0047539

Dymond, S., Schlund, M. W., Roche, B., Whelan, R., Richards, J., \& Davies, C. (2011). Inferred threat and safety: Symbolic generalization of human avoidance learning. Behaviour Research and Therapy, 49, 614-621.

Grillon, C., Baas, J. M. P., Cornwell, B., \& Johnson, L. (2006). Context conditioning and behavioral avoidance in a virtual reality environment: Effect of predictability. Biological Psychiatry, 60, 752-759.

Hall, G. (1996). Learning about associatively activated stimulus representations: Implications for acquired equivalence and perceptual learning. Learning $\xi^{\circ}$ Bebavior, 24, 233-255.

Hall, J. F. (1984). Backward conditioning in Pavlovian type studies: Reevaluation and present status. The Pavlovian Journal of Biological Science, 19, 163-168.

Hayes, S. C., \& Hayes, L. J. (1992). Verbal relations and the evolution of behaviour analysis. American Psychologist, 47, 1383-1395.

Hayes, S. C., Strosahl, K. D., \& Wilson, K. G. (2011). Acceptance and commitment therapy: The process and practice of mindful change (2nd ed.). New York, NY: Guilford.

Hermans, D., Craske, M. G., Mineka, S., \& Lovibond, P. F. (2006). Extinction in human fear conditioning. Biological Psychiatry, 60, 361-368.

Higgins, S. T., \& Morris, E. K. (1984). Generality of free-operant avoidance conditioning to human behaviour. Psychological Bulletin, 96, 247-272.

Holland, P. C. (1990). Event representation in Pavlovian conditioning: Image and action. Cognition, 37, 105-131.

Hooper, N., Saunders, S., \& McHugh, L. (2010). The derived generalization of thought suppression. Learning and Behavior, 38, 160-168.

Huijding, J., Mayer, B., Koster, E. H., \& Muris, P. (2011). To look or not to look: An eye movement study of hypervigilance during change detection in high and low spider fearful students. Emotion, 11, 666-674.

Kircanski, K., Lieberman, M. D., \& Craske, M. G. (2012). Feelings into words: Contributions of language to exposure therapy. Psychological Science, 23, 1086-1091.

Lang, P. J., Bradley, M. M., \& Cuthbert, B. N. (2005). International Affective Picture System (IAPS): Affective ratings of pictures and instruction manual (Tech. Rep. No. A-6). Gainesville, FL: University of Florida, Center for Research in Psychophysiology.
LeBeau, R. T., Glenn, D., Liao, B., Wittchen, H.-U., Beesdo-Baum, K., Ollendick, T., \& Craske, M. G. (2010). Specific phobia: A review of DSM-IV specific phobia and preliminary recommendations for DSM-V. Depression and Anxiety, 27, 148-167.

Lissek, S., Powers, A. S., McClure, E. B., Phelps, E. A., Woldehawariat, G., Grillon, C., \& Pine, D. S. (2005). Classical fear conditioning in the anxiety disorders: A meta-analysis. Behaviour Research and Therapy, 43, 1391-1424.

Lissek, S., Rabin, S., Heller, R. E., Lukenbaugh, D., Geraci, M., Pine, D. S., \& Grillon, C. (2010). Overgeneralization of conditioned fear as a pathogenic marker of panic disorder. American Journal of Psychiatry, 167, 47-55.

Lommen, M., Engelhard, I., \& van den Hout, M. (2010). Neuroticism and avoidance of ambiguous stimuli: Better safe than sorry? Personality and Individual Differences, 49, 1001-1006.

MacLeod, C., \& Cohen, I. L. (1993). Anxiety and the interpretation of ambiguity: A text comprehension study. Journal of Abnormal Psychology, 102, 238-247.

Masuda, A., Feinstein, A. B., Wendell, J. W., \& Sheehan, S. T. (2010). Cognitive defusion versus thought distraction: A clinical rationale, training, and experiential exercise in altering psychological impacts of negative self-referential thoughts. Behavior Modification, 34, 520-538.

Merckelbach, H., Arntz, A., Arrindell, W. A., \& de Jong, P. J. (1992). Pathways to spider phobia. Bebaviour Research and Therapy, 30, 543-546.

Merckelbach, H., Arntz, A., \& de Jong, P. J. (1991). Conditioning experiences in spider phobics. Behaviour Research and Therapy, 29, 333-335.

Mineka, S., \& Oehlberg, K. (2008). The relevance of recent developments in classical conditioning to understanding the etiology and maintenance of anxiety disorders. Acta Psychologica, 127, 567-580.

Muris, P., \& Field, A. P. (2011). The role of verbal threat information in the development of childhood fear. "Beware the Jabberwock!" Clinical Child \& Family Psychology Review, 13, 129-150.

Muris, P., \& Merckelbach, H. (1996). A comparison of two spider fear questionnaires. Journal of Behavior Therapy and Experimental Psychiatry, 27, 241-244.

Olsson, A., \& Phelps, E. A. (2004). Learned fear of "unseen" faces after Pavlovian, observational, and instructed fear. Psychological Science, 15, 822-828.

Olsson, A., \& Phelps, E. A. (2007). Social learning of fear. Nature Neuroscience, 10, 1095-1102. 
Pace-Schott, E. F., Verga, P. W., Bennett, T. S., \& Spencer, R. M. C. (2012). Sleep promotes consolidation and generalization of extinction learning in simulated exposure therapy for spider fear. Journal of Psychiatric Research, 46, 1036-1044.

Pflugshaupt, T., Mosimann, U. P., von Wartburg, R., Schmitt, W., Nyffeler, T., \& Muri, R. M. (2005). Hypervigilance-avoidance pattern in spider phobia. Journal of Anxiety Disorders, 19, 105-116.

Raio, C. M., Carmel, D., Carrasco, M., \& Phelps, E. A. (2012). Nonconscious fear is quickly acquired but swiftly forgotten. Current Biology, 22, 477-479.

Rinck, M., \& Becker, E. S. (2007). Approach and avoidance in fear of spiders. Journal of Behavior Therapy and Experimental Psychiatry, 38, 105-120.

Rodriguez-Valverde, M., Luciano, C., \& BarnesHolmes, D. (2009). Transfer of aversive respondent elicitation in accordance with equivalence relations. Journal of the Experimental Analysis of Behavior, 92, 85-111.

Sidman, M. (1994). Equivalence relations and behavior: A research story. Boston, MA: Authors' Cooperative.

Smeets, P. M., \& Barnes-Holmes, D. (2003). Children's emergent preferences for soft drinks: Stimulus equivalence and transfer. Journal of Economic Psychology, 24, 603-618.

Spetch, M. L., Wilkie, D. M., \& Pinel, J. P. J. (1981). Backward conditioning: A reevaluation of the empirical evidence. Psychological Bulletin, 89, 163-175.

Stinson, F., Dawson, D., Chou, S., Smith, S., Goldstein, R. B., Ruan, W. J., \& Grant, B. F. (2007). The epidemiology of DSM-IV specific phobia in the USA: Results from the National Epidemiologic Survey on Alcohol and Related Conditions. Psychological Medicine, 37, 1047-1059.
Szymanski, J., \& O’Donohue, W. (1995). Fear of spiders questionnaire. Journal of Behavior Therapy and Experimental Psychiatry, 26, 31-34.

Thorpe, S. J., \& Salkovskis, P. M. (1997). Animal phobias. In D. C. L. Davey (Ed.), Phobias: A handbook of theory, research and treatment (pp. 81-106). Chichester: Wiley.

Urcuioli, P. J. (1996). Acquired equivalence and mediated generalization in pigeon's matching to sample. In T. R. Zentall \& P. M. Smeets (Eds.), Stimulus class formation in humans and animals (pp. 55-70). Amsterdam: Elsevier.

Urcuioli, P. J., Zentall, T. R., \& DeMarse, T. (1995). Transfer to derived sample-comparison relations by pigeons following many-to-one versus one-to-many matching with identical training relations. Quarterly Journal of Experimental Psychology, 48, 158-178.

Vansteenwegen, D., Vervliet, B., Iberico, C., Baeyens, F., Van den Bergh, O., \& Hermans, D. (2007). The repeated confrontation with videotapes of spiders in multiple contexts attenuates renewal of fear in spider-anxious students. Behaviour Research and Therapy, 45, 1169-1179.

Vervliet, B., Kindt, K., Vansteenwegen, D., \& Hermans, D. (2010). Fear generalization in humans: Impact of prior non-fearful experiences. Behaviour Research and Therapy, 48, 1078-1084.

Ward-Robinson, J., \& Hall, G. (1996). Backward sensory preconditioning. Journal of Experimental Psychology: Animal Behavior Processes, 22, 395-404.

White, K., \& Davey, G. C. L. (1989). Sensory preconditioning and UCS inflation in human "fear" conditioning. Behaviour Research and Therapy, 27, 161-166. 